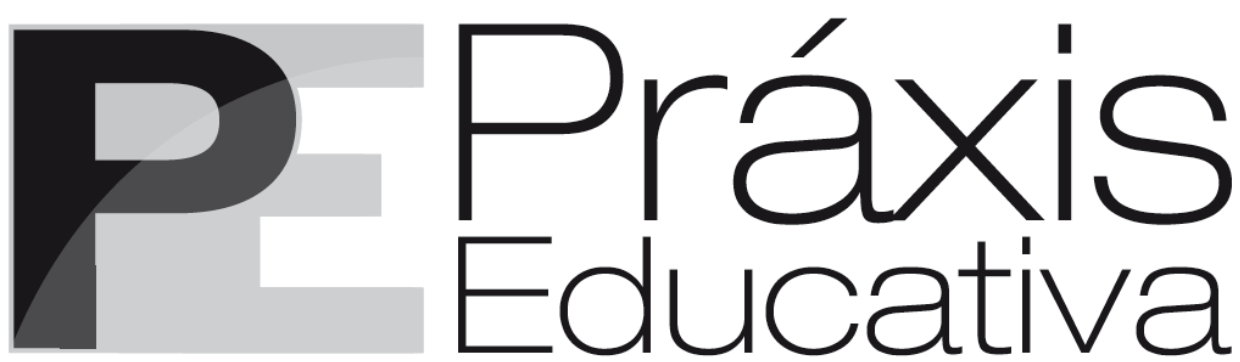

ISSN 1809-4031

elSSN 1809-4309

http://dx.doi.org/10.5212/PraxEduc.v.14n3.002

\title{
Imprensa, Primeira República e projeto civilizatório em pesquisas sobre a história da Educação
}

\section{Press, First Republic and civilization project in research on the history of Education}

\section{Prensa, Primera República y proyecto civilizatorio en investigaciones sobre la historia de la Educación}

\author{
Sandra do Rocio Ferreira Leal ${ }^{*}$ \\ Maria Isabel Moura Nascimento ${ }^{* *}$
}

Resumo: Este artigo analisa teses e dissertações que utilizaram a imprensa como fonte primária e/ou objeto de análise, cujo recorte temporal incluiu a primeira década da Primeira República e o projeto liberal civilizatório desse período. Esta pesquisa foi realizada por meio da Plataforma Sucupira, em 2017, em todos os programas de Pós-Graduação em Educação, linha de pesquisa História da Educação. Os resultados evidenciam que a imprensa era uma importante disseminadora do ideário liberal em iniciativas que propunham projetos civilizatórios para o Brasil republicano. Além disso, identifica temas e abordagens teórico-metodológicas privilegiadas nas pesquisas sobre imprensa, no início da Primeira República, na área da História da Educação, com destaque para os resultados encontrados.

Palavras-chave: Imprensa. Primeira República. Projeto civilizatório.

\begin{abstract}
This paper analyzes doctoral dissertations and master's theses that used the press as a primary source and/or as an object of analysis, whose temporal cutoff included the first decade of the First Republic and the liberal civilizing project of that period. This research used the Sucupira Plataform in 2017 in all the programs of Graduate studies in Education, line of research History of the Education. The results point out that the press was an important means to disseminate the liberal ideal in initiatives that proposed civilization projects for the republican Brazil. In addition, it identifies themes and the most used theoretical-methodological approaches in research about press in the beginning of the First Republic, in the area of History of Education, highlighting the results found.
\end{abstract}

Keywords: Press. First Republic. Civilization Project.

\footnotetext{
* Doutoranda do Programa de Pós-Graduação em Educação (PPGE) da Universidade Estadual de Ponta Grossa (UEPG). E-mail: <sandra_rfl@yahoo.com.br>. ORCID: https://orcid.org/0000-0003-1572-0329

** Professora da UEPG. Bolsista de Produtividade em Pesquisa - CNPq. E-mail: <misabelnasc@gmail.com>. ORCID: https://orcid.org/0000-0001-6243-9973
} 
Resumen: Este artículo analiza tesis y disertaciones que utilizan la prensa como fuente primaria $\mathrm{y} / \mathrm{u}$ objeto de análisis, cuyo recorte temporal incluye la primera década de la Primera República y el proyecto liberal civilizatorio de ese período. Esta investigación fue realizada por medio de la Plataforma Sucupira, en 2017, en todos los programas de postgrado en Educación, línea de investigación Historia de la Educación. Los resultados evidencian que la prensa era una importante diseminadora del ideario liberal en iniciativas que proponían proyectos civilizatorios para el Brasil republicano. Además de eso, identifica temas y enfoques teórico-metodológicos privilegiados en las investigaciones sobre prensa, en el inicio de la Primera República, en el área de la Historia de la Educación, con destaque para los resultados encontrados.

Palabras clave: Prensa. Primera República. Proyecto civilizatorio.

\section{Introdução}

Este artigo em tela resulta de uma pesquisa denominada Estado do Conhecimento ${ }^{1}$, que objetiva o levantamento de teses e de dissertações que utilizam a imprensa como fonte primária e/ou objeto de análise e que contemplaram, como recorte temporal, a primeira década da Primeira República $\left(1890\right.$ - 1900) e o projeto liberal civilizatório ${ }^{2}$ desse período. Esse levantamento foi realizado na Plataforma Sucupira ${ }^{3}$, nos programas de Pós-Graduação em Educação, linha de pesquisa História da Educação, durante o segundo semestre de 2017.

A opção por esse tipo de pesquisa justifica-se pelas contribuições que a imprensa, como fonte primária e objeto de análise, tem proporcionado à história da Educação. Estudos que visam identificar a produção científica de determinados temas e abordagens, em cursos de Mestrado e Doutorado, contribuem para que novas pesquisas avancem a partir do que já foi produzido nestes 53 anos de existência da Pós-Graduação em Educação no Brasil.

Em uma perspectiva histórica, é importante lembrar que a Pós-Graduação no Brasil foi criada como forma de "alavancar" a "[...] sociedade brasileira, para que o desenvolvimento científico e tecnológico fosse definido como uma área estratégica [...] pelo projeto de "Brasil grande' ou 'Brasil potência', acalentado pelos militares no exercício do poder político" (SAVIANI, 2008, p. 308).

No ano de 1965, foi criado e aprovado o primeiro Mestrado em Educação no Brasil, oferecido pela Pontifícia Universidade Católica do Rio de Janeiro (PUC-Rio). A partir dessa iniciativa pioneira, ainda que não se tenha um país que valorize e incentive a pesquisa, não se pode negar que houve um crescimento dos programas de Pós-Graduação, principalmente nos últimos anos (BIANCHETTI; FÁVERO, 2005).

\footnotetext{
${ }^{1}$ Estado da arte ou estado do conhecimento são pesquisas “[...] de caráter bibliográfico, elas parecem trazer em comum o desafio de mapear e de discutir uma certa produção acadêmica em diferentes campos do conhecimento, tentando responder que aspectos e dimensões vêm sendo destacados e privilegiados em diferentes épocas e lugares, de que formas e em que condições têm sido produzidas certas dissertações de mestrado, teses de doutorado, publicações em periódicos e comunicações em anais de congressos e de seminários” (FERREIRA, 2002, p. 258).

2 Projeto civilizatório ou de modernidade é compreendido, neste artigo, como projeto liberal capitalista que consolida o ideário republicano defendido pela classe burguesa brasileira no início da Primeira República.

3 Cursos avaliados e reconhecidos por área de avaliação e por região. Disponível em: <https://sucupira.capes.gov.br/sucupira >. Acesso em: 20 fev. 2018.
}

Práxis Educativa, Ponta Grossa, v. 14, n. 3, p. 832-846, set./dez. 2019 Disponível em: <http://www.revistas2.uepg.br/index.php/praxiseducativa> 
No início da caminhada da Pós-Graduação em terras brasileiras, as ricas experiências iniciais aliadas à estrutura "[...] do modelo americano com a densidade teórica resultante da influência europeia, acabou por produzir um modelo novo, de certo superior àqueles que lhe deram origem" (SAVIANI, 2000, p. 17).

Esse desenvolvimento da Pós-Graduação com características e necessidades da realidade brasileira vem acontecendo tanto de forma quantitativa, com o crescente número de programas e cursos criados, quanto em termos qualitativos, com uma vasta e significativa produção acadêmica dos corpos docentes dos programas e dos seus respectivos mestrandos e doutorandos, por meio de artigos, de dissertações e de teses.

Segundo dados extraídos da Plataforma Sucupira ${ }^{4}$, em 2017, na área da Educação, o Brasil possuía 74 programas de Mestrado e Doutorado acadêmico e 47 programas de Mestrado profissional. Esses programas desenvolviam 130 cursos de Mestrado acadêmico, 47 cursos de Mestrado profissional e, em algumas instituições de Ensino Superior, 74 cursos de Mestrado e Doutorado acadêmico que ocorriam de forma paralela.

É notório que ensino, pesquisa e extensão formam o tripé que deve sustentar os cursos de Graduação. Já na Pós-Graduação, que visa ampliar e aprofundar a formação inicial, o ensino é o eixo central dos cursos lato sensu, isto é, especializações e atualizações. A pesquisa, nesses cursos, ocorre como um exercício de reflexão e de escrita acadêmica.

Em contraposição, o elemento definidor da pós-graduação stricto sensu é a pesquisa, a qual determina o objetivo a ser alcançado para o qual o ensino concorre como uma mediação destinada a dispor e garantir os requisitos para o desenvolvimento da pesquisa que será a pedra de toque da formação pretendida. (SAVIANI, 2000, p. 2).

Essa formação pretendida tem, portanto, exigido que os pesquisadores tenham clareza em relação aos aspectos epistemológicos das pesquisas que desenvolvem, principalmente em Educação. Isso influi diretamente nos resultados obtidos, na qualidade das dissertações e das teses produzidas e no fortalecimento dessa área de pesquisa.

Em contrapartida, um outro aspecto importante a ser considerado é que se vive na PósGraduação as mesmas pressões de que são vítimas os trabalhadores em geral. "Metas são permanentemente definidas a estudantes e professores, que precisam buscá-las, sob o risco de serem desligados dos programas ou de serem expostos perante o grupo e taxados como improdutivos" (MENDES; IORA, 2014, p. 176). Nessa corrida desenfreada para o cumprimento dessas metas, corre-se o risco de desqualificar o trabalho acadêmico, estagnando-o, reproduzindo conhecimentos já elaborados em pesquisas que pouco ou nada contribuem.

Toda a criatividade e a espontaneidade ligadas ao processo de publicação de um trabalho científico são substituídas por um automatismo amorfo, uma obrigação sem crítica que, como um cão que persegue loucamente a própria cauda, é incapaz de parar e questionar o que está sendo feito. (CHAUÍ-BERLINK, 2004, p. 59 apud MENDES; IORA, 2014, p. 177).

Para que esse automatismo não se torne um círculo vicioso, uma boa opção tem sido a realização de pesquisas sobre o estado do conhecimento, pois contribuem para que haja um avanço qualitativo na produção científica, de modo a fortalecer e ampliar os campos de pesquisa, especialmente o da Educação. Além disso, cada mapeamento realizado é um registro histórico

\footnotetext{
4 A Plataforma Sucupira é uma “[...] nova e importante ferramenta para coletar informações, realizar análises e avaliações e ser a base de referência do Sistema Nacional de Pós-Graduação (SNPG). A escolha do nome é uma homenagem ao professor Newton Sucupira, autor do Parecer n $n^{\circ} 977$ de 1965. O documento conceituou, formatou e institucionalizou a pós-graduação brasileira nos moldes como é até os dias de hoje” (CAPES, 2014, n. p.).
}

Práxis Educativa, Ponta Grossa, v. 14, n. 3, p. 832-846, set./dez. 2019 Disponível em: <http://www.revistas2.uepg.br/index.php/praxiseducativa> 
quantitativo e qualitativo das produções científicas da Pós-Graduação brasileira, que contribui para caracterizar o perfil dos pesquisadores e avaliar as contribuições das dissertações e das teses produzidas.

A partir dessas reflexões, sob a perspectiva da valorização das pesquisas em Educação, serão apresentadas as trajetórias percorridas e as análises realizadas em dissertações e teses que abordam a história da Educação, no início da Primeira República, por meio da imprensa.

\section{Plataforma Sucupira como ferramenta de pesquisa: procedimentos metodológicos}

Antes do acesso à Plataforma Sucupira, foram determinados alguns critérios norteadores para a seleção das teses e das dissertações:

- Programas de Pós-Graduação em Educação, linha de pesquisa História da Educação.

- Cursos de Mestrado acadêmico. brasileira.

- Pesquisas cujo recorte temporal contemplasse a primeira década da Primeira República

- Estudos que utilizaram a imprensa (jornais, revistas literárias educacionais e boletins) como fonte primária e ou objeto de análise.

- Trabalhos que trataram da construção e da disseminação de projetos civilizatórios, de modernidade, de modernização, liberais, republicano, de progresso e outros termos afins, sob a égide do ideário liberal.

- Teses e dissertações defendidas a partir de 2007, dando continuidade à pesquisa de Zanlorenzi (2018), que se assemelha a esta investigação, a qual abrangeu o período de 1970 a $2011^{5}$.

À luz dos critérios elencados, recorreu-se à Plataforma Sucupira entre os meses de agosto e outubro de 2017. Foram acessados os cursos avaliados e reconhecidos pelo Ministério da Educação (MEC), por região (Norte, Nordeste, Centro-Oeste, Sudeste e Sul). Todas as instituições de Ensino Superior foram acessadas com o intuito de verificar se dispunham de programas de Pós-Graduação em Educação. Ao localizar esses programas, foram deixados de lado os Mestrados profissionais ${ }^{6}$. A pesquisa ocorreu nos Mestrados acadêmicos e nos cursos de Doutorado. Ainda com o objetivo de refinar a busca, selecionaram-se os programas que apresentavam a linha de pesquisa História da Educação de forma explícita ou incluída em outras linhas de pesquisa, como na de Políticas Públicas e outras.

\footnotetext{
5 Zanlorenzi é membro do grupo de pesquisa História, Sociedade e Educação no Brasil (HISTEDBR) Campos Gerais do qual também participamos. Em sua pesquisa, dos 50 trabalhos encontrados, foram selecionadas duas teses e três dissertações para análise, sendo a mais recente a de 2007. A partir desse estudo, é que definimos, no grupo de pesquisa, o período de investigação das teses e das dissertações (2007-2017). Para saber mais a respeito, ver ZANLORENZI, C. P. A imprensa periódica na pesquisa sobre história da educação: um estado do conhecimento. Revista HISTEDBR on-line. Campinas, v. 18, n. 2(76), p. 385-400, abr./jun. 2018.

${ }^{6}$ A opção por não selecionar dissertações dos mestrados profissionais em Educação se deve ao fato de que elas discutem aspectos teórico-metodológicos relacionados à prática educacional e não à história da Educação, foco desta pesquisa.
} 
A partir dos programas de Pós-Graduação em Educação, linha de pesquisa História da Educação, foram acessados ${ }^{7}$ os bancos de dissertações e teses das instituições e selecionadas sete dissertações de Mestrado e três teses de Doutorado. Todos os trabalhos estão organizados no Quadro 1, em ordem crescente, levando-se em consideração o ano de defesa.

Quadro 1 - Dissertações e teses selecionadas

\begin{tabular}{|c|c|c|c|c|}
\hline $\begin{array}{l}\text { Dissertação } \\
\text { Tese }\end{array}$ & Título & Autor(a) & Ano & Instituição \\
\hline 1- Dissertação & $\begin{array}{l}\text { Inquietações modernas: discurso } \\
\text { educacional e civilizacional no periódico } \\
\text { A Escola }(1906-1910)\end{array}$ & $\begin{array}{l}\text { Caroline Baron } \\
\text { Marach }\end{array}$ & 2007 & $\begin{array}{l}\text { Universidade Federal do } \\
\text { Paraná-UFPR }\end{array}$ \\
\hline 2- Dissertação & $\begin{array}{l}\text { Intelectuais, modernidade e discurso } \\
\text { educativo no jornal "Diário dos Campos" } \\
\text { (1907-1928) }\end{array}$ & $\begin{array}{l}\text { Eliezer Felix de } \\
\text { Souza }\end{array}$ & 2010 & $\begin{array}{l}\text { Universidade Estadual de } \\
\text { Ponta Grossa - UEPG }\end{array}$ \\
\hline 3- Dissertação & $\begin{array}{l}\text { O impresso como estratégia de intervenção } \\
\text { social: educação e bistória na perspectiva } \\
\text { de Dario Vellozo }(1885 \text { - 1937) }\end{array}$ & $\begin{array}{l}\text { Ernando Brito } \\
\text { Gonçalves Junior }\end{array}$ & 2011 & $\begin{array}{l}\text { Universidade Federal do } \\
\text { Paraná-UFPR }\end{array}$ \\
\hline 4- Dissertação & $\begin{array}{l}\text { O projeto republicano para a educação no } \\
\text { Paraná e o processo de (des) mistificação } \\
\text { de Júlia Wanderley }\end{array}$ & $\begin{array}{l}\text { Nilvan Laurindo } \\
\text { Sousa }\end{array}$ & 2013 & $\begin{array}{l}\text { Universidade Estadual de } \\
\text { Ponta Grossa - UEPG }\end{array}$ \\
\hline 5- Dissertação & $\begin{array}{l}\text { Jornal O Albor } e \quad a \\
\text { produção/disseminação de feminilidades } \\
\text { na imprensa lagunense- }\end{array}$ & $\begin{array}{l}\text { Fabrícia Machado } \\
\text { Fernandes }\end{array}$ & 2014 & $\begin{array}{l}\text { Universidade do Sul de } \\
\text { Santa Catarina - UNISUL }\end{array}$ \\
\hline 6- Dissertação & $\begin{array}{l}\text { Os anúncios no jornal A União (1904- } \\
\text { 1937): a propagação da modernidade } \\
\text { pedagógica na Paraíba }\end{array}$ & $\begin{array}{l}\text { Kalyne Barbosa } \\
\text { Arruda }\end{array}$ & 2015 & $\begin{array}{l}\text { Universidade Federal da } \\
\text { Paraíba-UFPB }\end{array}$ \\
\hline 7- Dissertação & $\begin{array}{l}\text { Álbum das meninas, revista literária e } \\
\text { educativa dedicada às jovens brasileiras: } \\
\text { estudo de um impresso de Anália Franco } \\
\text { (1898-1901) }\end{array}$ & $\begin{array}{l}\text { Floriza } \quad \text { Garcia } \\
\text { Chagas }\end{array}$ & 2016 & $\begin{array}{l}\text { Universidade Federal de } \\
\text { São Paulo-USP }\end{array}$ \\
\hline 8- Tese & $\begin{array}{l}\text { Clube Curitibano: representações de laz̧er } \\
\text { na formação da sociedade curitibana }\end{array}$ & Marcelo Pastre & 2009 & $\begin{array}{l}\text { Universidade Metodista } \\
\text { de Piracicaba - UNIMEP }\end{array}$ \\
\hline 9- Tese & $\begin{array}{l}\text { A expressão do liberalismo na revista } A \\
\text { escola }(1906 \text { - 1910) no Paraná }\end{array}$ & $\begin{array}{ll}\text { Claudia Maria } \\
\text { Petchak } \\
\text { Zanlorenzi }\end{array}$ & 2014 & $\begin{array}{l}\text { Universidade Estadual de } \\
\text { Ponta Grossa - UEPG }\end{array}$ \\
\hline 10- Tese & $\begin{array}{l}\text { Civilização, modernidade e educação nas } \\
\text { páginas do jornal A Razão (1898 - } \\
\text { 1923) }\end{array}$ & $\begin{array}{l}\text { Ana Marcia } \\
\text { Barbosa } \\
\text { Santana Costa }\end{array}$ & 2017 & $\begin{array}{l}\text { Universidade Federal de } \\
\text { Sergipe-UFS }\end{array}$ \\
\hline
\end{tabular}

Fonte: Plataforma Sucupira. Organização das autoras.

As dissertações e as teses apresentadas no Quadro 1 serão analisadas na próxima seção.

\footnotetext{
7 Alguns programas de Pós-Graduação em Educação apresentaram problemas técnicos em seus sites, impossibilitando o acesso.
}

Práxis Educativa, Ponta Grossa, v. 14, n. 3, p. 832-846, set./dez. 2019 Disponível em: <http://www.revistas2.uepg.br/index.php/praxiseducativa $>$ 


\section{História da Educação brasileira na imprensa: análise das dissertações e das teses}

Após a seleção das teses e das dissertações, realizou-se a leitura dos resumos, palavraschave, sumários, introduções e, em alguns casos, capítulos na íntegra, considerações finais e referências com o intuito de analisar os trabalhos.

A dissertação de Mestrado de Marach (2007), Inquietações modernas: discurso educacional e civilizacional no periódico A Escola (1906 - 1910), e a tese de Doutorado de Zanlorenzi (2014), A expressão do liberalismo na revista A escola (1906 - 1910) no Paraná, apesar de não compartilharem dos mesmos fundamentos epistemológicos, utilizam o mesmo recorte temporal (1906-1910) e a mesma fonte primária, a revista $A$ Escola, que foi criada em 1906, em Curitiba, pelo Grêmio de Professores Públicos do Paraná, a qual circulou até 1910 na capital paranaense.

Marach (2007) visa à compreensão da ambiência cultural presente na primeira década do século XX por meio da análise dos discursos materializados nos artigos dos intelectuais paranaenses colaboradores da revista $A$ Escola, que a autora caracteriza como a elite letrada de Curitiba, denominando-os, em seu estudo, de "educacionistas" (MARACH, 2007). Trata-se, portanto, de uma análise histórico-linguística dos artigos veiculados na revista, respaldada por Pocock e Miceli (2003), visando captar a "[...] concepção de modernidade elaborada pelos intelectuais daquele contexto, bem como a uma gama de crenças e posturas que asseguraram sua identidade" (MARACH, 2007, p. 21). Em decorrência disso, sob o viés da História Intelectual ${ }^{8}$, a pesquisadora afirma que “[...] o intelectual é entendido aqui como um 'ator lingüístico' que elabora seu discurso, seus atos de fala, e cria inovações de modo a legitimar sua concepção de mundo e seus projetos" (MARACH, 2007, p. 20). Percebe-se também que Marach faz menção à formação da República e às ideias liberais que permeavam a sociedade da época e que influenciavam as produções educacionais e literárias dos colaboradores da revista que atuavam nessas duas instâncias.

A respeito da presença do ideário liberal na revista $A$ Escola e a constituição do estado republicano, Zanlorenzi (2014, p. 6) aprofunda e amplia essa discussão em sua tese, com o intuito de "[...] identificar as influências do liberalismo na educação, nas mudanças do trabalho docente e na propagação do método intuitivo como modelo ideal de ensino". Constata-se também no trabalho de Zanlorenzi que há uma sólida discussão em torno da educação moderna, também chamada de pedagogia moderna, vista como ideal para resolver os problemas educacionais naquele período histórico, dando ares de modernidade à educação paranaense.

A pesquisadora utiliza o aporte teórico-metodológico do Materialismo Histórico que parte da compreensão de que "[...] ideias educacionais veiculadas nesses impressos são a expressão do contexto histórico de forma imediata e dos interesses subjacentes, dado ser determinada pelos modos de produção" (ZANLORENZI, 2014, p. 13). Essa postura investigativa assumida pela autora é apoiada por Marx (1991) que assevera que, na "[...] produção social da própria vida, os homens contraem relações, necessárias, independentes da sua vontade, relações de produção que correspondem a uma etapa determinada de desenvolvimento das forças produtivas materiais" (MARX, 1991, p. 3).

\footnotetext{
8 A "história intelectual diz respeito às diversas interpretações sobre os agentes, as práticas, os processos e os produtos classificáveis como intelectuais. Estudos esses de importância ímpar, uma vez que os agentes - sejam homens de cultura e saber - e suas práticas estiveram presentes e atuantes em todos os processos históricos de grande envergadura. Esses atores sociais usaram suas habilidades de discutir, argumentar, projetar o futuro a serviço de combates políticos, o que demonstra a relevância dos intelectuais nas sociedades, como detentores do poder ideológico" (WASSERMAN, 2015, p. 63).
}

Práxis Educativa, Ponta Grossa, v. 14, n. 3, p. 832-846, set./dez. 2019 Disponível em: <http://www.revistas2.uepg.br/index.php/praxiseducativa> 
Embora as duas pesquisadoras utilizem a mesma fonte primária em um mesmo recorte temporal, suas abordagens diferenciam-se pelos objetivos e pelos fundamentos epistemológicos. No entanto, é inegável que os dois trabalhos oferecem contribuições importantes para o conhecimento e a compreensão da história da Educação do Paraná.

Ainda dentro do cenário paranaense, tem-se a dissertação intitulada Intelectuais, modernidade e discurso educativo no jornal "Diário dos Campos" (1907-1928), de Souza (2010). Esse periódico foi fundado no ano de 1907, na cidade de Ponta Grossa-PR, com o nome de O Progresso. Mais tarde, o nome do jornal foi mudado para Diário dos Campos e, atualmente, ainda circula na cidade com esse mesmo nome (SOUZA, 2010).

O estudo em questão objetivou "[...] a análise da presença dos debates nacionais sobre educação no discurso do jornal Diário dos Campos” (SOUZA, 2010, p. 9). Por meio dessa análise, Souza problematizou as convergências e as divergências nos discursos dos intelectuais do período pesquisado, no âmbito municipal e estadual, que circulavam no meio educacional. O pesquisador fundamenta sua análise em Bakhtin e afirma que "[...] o fundamental na sua teoria do discurso é a ressalva à significação do dizer, privilegiando aquilo que está aquém e além da estrutura, isto é, o já dito e os efeitos do sentido do dizer em dada circunstância” (SOUZA, 2010, p. 15). Ele também utiliza o conceito de intelectual com organizador da cultura, proposto por Gramsci. Essa dissertação insere-se na História Intelectual e tem como questão central: “[...] quais intelectuais coordenaram o processo de constituição do jornal e que discursos educativos promoveram nesse espaço cultural?" (SOUZA, 2010, p. 9).

O estudo de Souza (2010) aproxima-se do estudo de Marach (2007), pois ambos analisam os discursos dos intelectuais colaboradores de periódicos paranaenses, de forma a inserir suas pesquisas na História Cultural. No entanto, essas análises são fundamentadas por autores diferentes. Souza utiliza Mikhail Bakhtin, e Marach respalda sua análise no contextualismo linguístico, idealizado por Quentin Skinner e John Pocock.

Já a dissertação de Mestrado de Sousa (2013), O projeto republicano para a educação no Paraná e o processo de (des)mistificação de Júlia Wanderley, aproxima-se dos estudos de Marach (2007), Zanlorenzi (2014) e Souza (2010) no enfoque da história da Educação paranaense. A pesquisadora explicita no resumo do trabalho que seu "[...] objetivo geral foi analisar a formação e a atuação profissional de Júlia Wanderley e sua participação junto à revista "A Escola"' (SOUSA, 2013, p. 11). Portanto, assim como Marach (2007) e Zanlorenzi (2014), faz-se presente, em seu estudo, o periódico $A$ Escola.

É importante também salientar alguns dos objetivos específicos de seu estudo, tais como: "[...] estudar Júlia Wanderley como um sujeito histórico, bem como a sua formação e atuação profissional; evidenciar o contexto em que Júlia Wanderley estava imersa [...]” (SOUSA, 2013, p. 11). Esses objetivos dão indícios dos fundamentos epistemológicos empregados, pois, ao considerar a educadora como um sujeito histórico e demonstrar a preocupação em evidenciar o contexto em que ela estava imersa, constata-se que a pesquisadora compreende que o homem é um ser de relações e que essas relações são estabelecidas no meio social onde ele vive. Para desnudar essa realidade material, em uma perspectiva teórico-metodológica marxiana, a autora utiliza o método do Materialismo Histórico. Nesse aspecto, seu estudo aproxima-se da tese de doutoramento de Zanlorenzi (2014).

Muito embora o trabalho de Sousa (2013) enfoque uma intelectual, não se insere na História Intelectual, perspectiva adotada por Marach (2007) e Souza (2010). A pesquisadora justifica sua opção epistemológica quando, fundamentada em Nascimento (2008), enfatiza a importância da apreensão da totalidade para evidenciar o sujeito imerso no contexto histórico

Práxis Educativa, Ponta Grossa, v. 14, n. 3, p. 832-846, set./dez. 2019 Disponível em: < http://www.revistas2.uepg.br/index.php/praxiseducativa> 
que o cerca. A esse respeito, Marx (2003) elucida que não podemos perder de vista “[...] o modo de produção da vida social, político e intelectual em geral. Não é a consciência dos homens que determina o seu ser; é o seu ser social que, inversamente, determina a sua consciência" (MARX, 2003, p. 5).

O trabalho de pesquisa $O$ impresso como estratégia de intervenção social: educaşão e história na perspectiva de Dario Vellozo (1885-1937), de Gonçalves Junior (2011), também se debruça sobre a história da Educação paranaense. O estudo em tela insere-se na História Cultural e apresenta como pergunta de pesquisa: "Como Dario Vellozo utilizou os impressos como mecanismos e a educação e a história como discursos de intervenções sociais?" (GONÇALVES JUNIOR, 2011, p. 19). Para resolver a problemática levantada, o pesquisador utilizou revistas e livros como fontes, "[...] alguns textos presentes nas revistas Club Curitibano (1891/1904), Azul (1893), O Cenáculo (1895/97) e A Escola (1906/1910)" (GONÇALVES JUNIOR, 2011, p. 19, grifos do autor). Três desses periódicos (Clube Curitibano; $O$ Cenáculo e $A$ Escola) também foram utilizados nos estudos de Marach (2007), Sousa (2013) e Zanlorenzi (2014).

Gonçalves Junior concluiu que “[...] Vellozo acreditava ser através de uma nova forma de educar o aluno que se poderia transformar a sociedade" (GONÇALVES JUNIOR, 2011, p. 93). Essa educação para ser transformadora deveria primar pela teoria aliada à prática e não poderia se restringir aos bancos escolares. A imprensa, na concepção de Vellozo, também era educativa, portanto ele escrevia: “[...] para diversos públicos sempre com o objetivo de transmitir suas ideias e de tentar cooptar mais adeptos para suas concepções teóricas" (GONÇALVES JUNIOR, 2011, p. 93).

Há também o estudo de Pastre (2009), intitulado Clube Curitibano: representações de lazer na formação da sociedade curitibana, que apresenta um estudo sobre o Clube Curitibano. Essa sociedade recreativa foi fundada em 25 de setembro de 1881, na capital paranaense, com o intuito de oferecer à burguesia um espaço nobre que agregasse cultura, educação, esporte e lazer.

A referida tese analisa mais especificamente as representações de lazer na formação da sociedade curitibana, utilizando como fonte primária a revista que leva o mesmo nome do clube e que foi criada em 1890. Esse periódico circulava entre os associados da agremiação com o intuito de informá-los sobre a programação social e esportiva do clube, bem como incentivá-los à leitura de obras em prosa e verso. Nessa tese, o aporte epistemológico são as Representações Sociais sob a perspectiva de Roger Chartier. A análise proposta evidencia a ideia do movimento sociedade clube - sociedade; assim, os grupos sociais estabelecidos transferem para o Clube Curitibano e para as atividades de lazer desenvolvidas na agremiação "[...] valores, comportamentos, formas de conduta e costumes, que são posteriormente devolvidos aos seus integrantes e pelas relações de interdependências existentes, transferidas também para toda sociedade" (PASTRE, 2009, p. 109).

Já a tese de Costa (2017), Civilização, modernidade e educação nas páginas do jornal A Rąãa (1898-1923), estuda a história da educação sergipana. A pesquisadora salienta a importância de estudar a imprensa que, "[...] alinhada ao ideário de civilização, progresso e modernidade vigente durante a República Velha, [...] exerceu um papel de destaque na veiculação de ideias e na propagação do conhecimento" (COSTA, 2017, p. 10).

O trabalho ora analisado é alicerçado pelos fundamentos epistemológicos da História Cultural, como alguns dos estudos anteriormente mencionados. A pesquisadora utiliza conceitos de Bourdieu, tais como: "campo", "capital" e "babitus", e de "representação", de Chartier, em consonância com as contribuições da História da Leitura e do Impresso. Enfatiza que o jornal $A$ Razão testemunhou, veiculou e formou opiniões a partir de "[...] um discurso [...] direcionado para a organização da sociedade no plano cultural e de progresso material, além da preservação

Práxis Educativa, Ponta Grossa, v. 14, n. 3, p. 832-846, set./dez. 2019 Disponível em: <http://www.revistas2.uepg.br/index.php/praxiseducativa $>$ 
da moralidade, daí a conformidade rigorosa com o passado, a valorização da terra natal, a ênfase na retidão moral e religiosa" (COSTA, 2017, p. 156).

O jornal analisado foi fundado em 1898 e circulou na cidade de Estância, em Sergipe, até o ano de 1923, quando começou a sofrer mudanças editoriais (COSTA, 2017). Um outro aspecto importante é que esse jornal é o objeto de análise dessa tese e também a fonte primária. Portanto, o estudo desse periódico trouxe à tona inúmeras temáticas, tais como:

[...] histórico acerca da imprensa em Sergipe, a missão civilizatória atribuída à imprensa no período republicano, a relação entre imprensa e literatura, um breve perfil da cidade de Estância, os indícios de livros que circularam na cidade na época por meio dos anúncios veiculados no jornal, a educação por meio das páginas do periódico, o incentivo às artes, notadamente, a música, o cinema e o teatro, a condição feminina pelos escritos publicados e a atuação dos médicos Jessé Fontes e Josafá Brandão nos campos cultural e educacional tendo a imprensa como veículo. (COSTA, 2017, p. 10).

Frente a tantas questões suscitadas nas páginas desse periódico, a pesquisadora defendeu a tese de que o jornal esteve imbuído de uma missão civilizatória e progressista, assumindo o papel de disseminador da leitura e da instrução em Estância, no Estado de Sergipe (COSTA, 2017).

Da história da Educação sergipana, passa-se para o Estado da Paraíba com o estudo de Arruda (2015), que analisou, por meio dos anúncios veiculados em um periódico, os projetos que visavam o progresso do Brasil. Sua dissertação, Os anúncios no jornal A União (1904-1937): a propagação da modernidade pedagógica na Paraíba, teve por objetivo "[...] analisar as representações de educação presentes nos anúncios sobre professores, escolas e métodos de ensino, no jornal A União, nos anos de 1904 a 1937” (ARRUDA, 2015, p. 9). Esse jornal foi criado em 2 de fevereiro de 1893 e selecionado como fonte de pesquisa por ser o maior periódico de circulação diária na Paraíba (ARRUDA, 2015).

A referida pesquisa enquadra-se na perspectiva teórico-metodológica da Nova História Cultural", "[...] que proporciona não só uma ampliação no conceito de fonte, como também na utilização que se pode fazer [...]" (ARRUDA, 2015, p. 18). Além disso, esse estudo utiliza o paradigma indiciário de Ginszburg (1989) ${ }^{10}$. Arruda (2015) conclui que os discursos no campo político e educacional, na Primeira República, são respaldados pelas ideias liberais republicanas de transformação social por meio da educação e afirma que

[...] analisar os anúncios referentes à educação, pautada no discurso de uma modernidade pedagógica, desvelam-se além do contexto educacional, fatos, valores e políticas cujas consequências ainda se fazem presentes na sociedade contemporânea, de forma implícita ou explícita. (ARRUDA, 2015, p. 67).

Foram selecionadas ainda mais duas dissertações que utilizam a imprensa como fonte primária e ou objeto de análise. Esses dois trabalhos investigam a educação dedicada à mulher por meio de um jornal de Laguna, em Santa Catarina, e de uma revista de São Paulo capital.

\footnotetext{
${ }^{9}$ Peter Burke (2008) divide a História Cultural em fases: Clássica, que ocorreu de 1800 a1850; História Social da Arte, que iniciou na década de 1930; História da Cultura Popular, que teve início na década de 1960; e Nova História Cultural, a partir da década de 1980.

10 “[...] conjunto de princípios e procedimentos que contém a proposta de um método heurístico centrado no detalhe, nos dados marginais, nos resíduos tomados enquanto pistas, indícios, sinais, vestígios ou sintoma. [...]. Os documentos oficiais, relatórios, decretos leis, fontes secundárias e voluntárias, ou seja, as fontes investigadas pelo pesquisador que, se submetidas à análise semiótica ou sintomal, podem revelar muito mais do que o testemunho tomado apenas como um dado" (RODRIGUES, 201-?, p. 1, grifos da autora).
}

Práxis Educativa, Ponta Grossa, v. 14, n. 3, p. 832-846, set./dez. 2019 Disponível em: <http://www.revistas2.uepg.br/index.php/praxiseducativa> 
O primeiro estudo é de Fernandes (2014), intitulado Jornal O Albor e a produção/disseminação de feminilidades na imprensa lagunense - 1901-1930. Em sua pesquisa, a autora utiliza referenciais da história das mulheres e das relações de gênero ${ }^{11}$ no contexto brasileiro dentro do seu recorte temporal. A pesquisadora também usa os conceitos de classe, de Thompson, de hegemonia, de Gramsci, e de ideologia, utilizado por Mészáros. Libâneo também se faz presente, para respaldar a discussão em torno da função pedagógica da imprensa (FERNANDES, 2014).

O jornal $O$ Albor, fonte primária e também objeto de análise do trabalho ora mencionado, foi fundado em 15 de setembro de 1901. Seu nome significa "alvorecer", anunciando o início de uma nova era, de um novo século, e com ele novas ideias de conhecimento e modernidade (FERNANDES, 2014). A análise proposta pela pesquisadora revelou que o jornal apresentava significados de modernidade fundamentados pelas ideias liberais. Essas ideias eram articuladas pelo Partido Republicano. O editor chefe e proprietário do jornal $O$ Albor era filiado a esse partido. Essas constatações evidenciam que a imprensa da época estava a serviço da classe dominante, disseminando ideias liberais que davam ao povo a falsa ideia de que todos tinham acesso irrestrito aos projetos de modernidade e progresso.

Em relação à educação das mulheres, a pesquisadora salienta que, em muitas publicações do jornal $O$ Albor, é explícita a ênfase à inferioridade feminina, considerada o ser sentimental. Já o homem era visto como o ser racional, inteligente. A educação das mulheres era voltada, portanto, ao ambiente doméstico, e, dos homens, para o espaço social (FERNANDES, 2014).

A dissertação de Fernandes (2014) contribui para a compreensão das “[...] representações das feminilidades e de como a imprensa também participava da produção dessas mesmas representações, ao selecionar, destacar, reforçar, negar posições políticas e ações ligadas às questões feministas no início do século" (FERNANDES, 2014, p. 93). A pesquisadora alerta que ainda há um vasto acervo a ser pesquisado, pois o jornal $O$ Albor encerrou suas atividades em 1964.

Para finalizar a análise dos estudos selecionados, tem-se a pesquisa de Chagas (2016), que analisa uma revista de caráter literário educativo. O título da dissertação, Álbum das meninas, revista literária e educativa dedicada às jovens brasileiras: estudo de um impresso de Anália Franco (1898-1901), já revela que se trata de um estudo voltado à história das mulheres, pois a referida revista, que foi criada em 1898 e circulou até 1901, trabalhava com questões literárias e educativas e era direcionada ao público feminino. A análise desse periódico mostrou que já havia na época a compreensão de que a arte não podia ficar à margem do processo educacional, pois desenvolvia a sensibilidade, aguçava os sentidos, motivava e despertava habilidades.

Segundo a pesquisadora, "[...] estudar esse impresso justifica-se por ser uma revista feminina com intencionalidade e projeto editorial bem definidos, também por ser um espaço próprio de expressão das ideias e projetos da proprietária, escritora e professora Anália Emília Franco (1853-1919)" (CHAGAS, 2016, p. 9). A análise desse periódico evidenciou o posicionamento político e social da referida educadora e literata.

O estudo em pauta adequa-se à perspectiva epistemológica da História Cultural. Chagas (2016) ressalta que:

\footnotetext{
11 Segundo Grossi, a discussão de gênero determina tudo que é social, cultural e historicamente definido e está em constante processo de ressignificação, em virtude das interações concretas entre indivíduos do sexo feminino e masculino" (GROSSI, 2000, p. 27 apud AMORIM, 2011, p. 7).
}

Práxis Educativa, Ponta Grossa, v. 14, n. 3, p. 832-846, set./dez. 2019 Disponível em: <http://www.revistas2.uepg.br/index.php/praxiseducativa> 
A revista como fonte/objeto tem tido espaço privilegiado nos trabalhos com aporte teórico metodológico da História Cultural, pois o tema de investigação não se reduz ao estudo do texto, mas tem se ampliado ao objeto material que é entendido como produto cultural. Ao tomar como objeto de análise não apenas o texto, mas também o portador, se produziram estratégias metodológicas voltadas para a análise dos mecanismos de produção, circulação e recepção do impresso. (CHAGAS, 2016, p. 30).

A autora utilizou a revista como fonte e também como objeto de análise com o intuito de compreender a "[...] cultura como expressão sintética das práticas, buscando identificar o papel educativo e literário do periódico no que diz respeito ao público leitor e às interações que o ligavam às formas de instrução e educação da mulher" (CHAGAS, 2016, p. 9).

A revista Álbum das Meninas, segundo as considerações finais de Chagas (2016), constituiuse à época como um importante espaço dos discursos de representação e de produção da mulher brasileira. Além disso, a revista proporcionava às leitoras o acesso às ideias feministas mundiais. Em contrapartida, o periódico mostrava-se mais conservador do que as demais revistas femininas, pois incentivava as mulheres a estudar e a trabalhar; no entanto, defendia que elas deveriam cuidar dos filhos, da casa e do marido. "Por fim, ao mesmo tempo em que os valores morais ligados à cultura religiosa cristã faziam parte dessa ambiência educativa, a política se constituía e conformava os papéis que os sujeitos, homens e mulheres, representariam na sociedade" (CHAGAS, 2016, p. 174).

Os estudos aqui analisados apresentam diferentes aportes epistemológicos, organizados no Quadro 2 para uma melhor visualização. São olhares diferentes sobre uma mesma fonte primária ou sobre fontes diferentes que oportunizam pontos de partida, análises, resultados e contribuições distintas para o campo da História da Educação. "A depender dos fundamentos que regem o olhar do pesquisador, vão se constituindo as tramas do conhecimento histórico e as relações mais específicas com o contexto educacional, ultrapassando os muros escolares" (ZANLORENZI, 2010, p. 61). 
Quadro 2 - Aportes epistemológicos nas pesquisas sobre a História da Educação brasileira

\begin{tabular}{|c|c|c|c|}
\hline Autor/autora & Aporte teórico-metodológico & Fonte primária & Recorte temporal \\
\hline Marach (2007) & $\begin{array}{l}\text { Quentin Skinner e John Pocock - } \\
\text { História Cultural. }\end{array}$ & Revista $A$ Escola & $1906-910$ \\
\hline Pastre (2009) & $\begin{array}{l}\text { Roger Chartier -Representações } \\
\text { Sociais. }\end{array}$ & $\begin{array}{l}\text { Revista } \quad \text { Clube } \\
\text { Curitibano }\end{array}$ & $1890-1898$ \\
\hline Souza (2010) & $\begin{array}{l}\text { Mikhail Bakhtin }- \text { História } \\
\text { Intelectual. }\end{array}$ & $\begin{array}{l}\text { Jornal Diário dos } \\
\text { Campos }\end{array}$ & $1907-1928$ \\
\hline Gonçalves Júnior (2011) & $\begin{array}{l}\text { Quentin Skinner - História } \\
\text { Intelectual. }\end{array}$ & $\begin{array}{l}\text { Revistas Club } \\
\text { Curitibano; Azul, O } \\
\text { Cenáculo e A Escola }\end{array}$ & $1885-1937$ \\
\hline Sousa (2013) & $\begin{array}{l}\text { Karl Marx e Friedrich Engels - } \\
\text { Materialismo Histórico. }\end{array}$ & Revista $A$ Escola & $1906-1910$ \\
\hline Fernandes (2014) & $\begin{array}{l}\text { Edward Palmer } \text { Thompson - } \\
\text { Conceito de } \text { Classe; Antonio } \\
\text { Gramsci - } \\
\text { Hegemonia. }\end{array}$ & Jornal $O$ Albor & $1901-1930$ \\
\hline Zanlorenzi (2014) & $\begin{array}{l}\text { Marx e Engels - Materialismo } \\
\text { Histórico. }\end{array}$ & Revista $A$ Escola & \\
\hline Arruda (2015) & $\begin{array}{l}\text { Ginszburg - Paradigma Indiciário. } \\
\text { Nova História Cultural. }\end{array}$ & Jornal A União & 1904-1937 \\
\hline Chagas (2016) & $\begin{array}{l}\text { Roger Chartier - Representações } \\
\text { Sociais. } \\
\text { História Cultural. }\end{array}$ & $\begin{array}{l}\text { Revista Album das } \\
\text { Meninas }\end{array}$ & 1898-1901 \\
\hline Costa (2017) & $\begin{array}{l}\text { Pierre Bourdieu - Campo, Capital, } \\
\text { Habitus; e Roger Chartier - } \\
\text { Representações Sociais. } \\
\text { História Cultural. }\end{array}$ & Jornal $A$ Razão & $1898-1923$ \\
\hline
\end{tabular}

Fonte: Teses e dissertações analisadas. Organização das autoras.

O Quadro 2 mostra que, dentro dos critérios estabelecidos, há um número maior de trabalhos que utilizam periódicos paranaenses, em especial a revista $A$ Escola, presente em três dissertações e uma tese.

Um aspecto importante é que em todas as dissertações e teses há clareza quanto ao aporte epistemológico adotado, pois os autores e as autoras indicam, já na introdução, qual a opção teórico-metodológica que adotarão, como procederão e são coerentes ao longo de suas pesquisas. Além disso, nos resumos e nas introduções, estão presentes os objetos de análise, perguntas de pesquisa, objetivos geral e específicos, fontes de pesquisa e referenciais teóricos que serão utilizados.

Há também de considerar-se que o período pesquisado em todos os trabalhos analisados é bastante fértil, pois se trata de uma época de transição da Monarquia à República. Como em toda mudança, tem-se a realidade aparente e a realidade latente, aquela que precisa ser desnudada, analisada e compreendida. Todos os periódicos analisados, teoricamente, compartilham do desejo de progresso, civilização e modernidade. No entanto, esses projetos republicanos liberais mascaram a sua essência, que é a manutenção do poder da classe burguesa em detrimento da continuidade da subjugação da classe trabalhadora. 
Com o intuito de desvelar essa essência liberal, é inegável, portanto, a importância da imprensa para as pesquisas sobre a história da Educação brasileira, pois seus registros e suas memórias

[...] resultam da ação histórica do homem e, mesmo que não tenham sido produzidas com a intencionalidade de registrar a sua vida e o seu mundo, acabam testemunhando o mundo dos homens em suas relações com outros homens e com o mundo circundante, a natureza, de forma que produza e reproduza as condições de existência e de vida. (LOMBARDI, 2004, p. 155).

No resgate e na compreensão da história da Educação brasileira, a imprensa é uma fonte inesgotável de pesquisa, uma porta sempre aberta a novas descobertas, a múltiplas interpretações. Cabe aos pesquisadores, a partir dos mapeamentos das pesquisas sobre o estado do conhecimento, realizarem mergulhos mais profundos em temas inéditos ou já pesquisados, sob perspectivas epistemológicas diferentes, utilizando como objeto de análise ou como fonte primária periódicos em evidência nos recortes temporais selecionados ou aqueles que ainda não foram explorados.

\section{Considerações finais}

O estudo ora realizado possibilitou o mapeamento da produção científica brasileira em História da Educação, de 2007 a 2017, que utilizou a imprensa como fonte primária e, também, como objeto de análise dos projetos civilizatórios, progressistas e de modernidade, do início da Primeira República. Muito além da constatação, esta pesquisa oportunizou o conhecimento dos fundamentos epistemológicos dos estudos selecionados para esta investigação, mostrando que há percursos teórico-metodológicos diferentes e bem definidos em pesquisas sobre a imprensa. Essa clareza epistemológica é fator determinante na qualidade das pesquisas de um modo geral e, sobremaneira, em Educação.

Pode-se concluir que, por meio do acesso à Plataforma Sucupira, foi possível identificar um grande número de teses e de dissertações acadêmicas que utilizam a imprensa como fonte primária e/ou como objeto de análise. Entretanto, muitos desses trabalhos não se enquadravam nos critérios de seleção estabelecidos. Esse mapeamento também revelou que ainda há muito a ser pesquisado em revistas, jornais e boletins, pois o "[...] passado é, portanto, uma dimensão permanente da consciência humana, um componente inevitável das instituições, valores e outros padrões da sociedade humana" (HOBSBAWM, 1998, p. 22), e a imprensa é, sem dúvida, uma das principais testemunhas desse passado.

\section{Referências}

AMORIM, L. T. de. Gênero: uma construção do movimento feminista? In: II SIMPÓSIO GÊNERO E POLÍTICAS PÚBLICAS, 2., 2011, Londrina. Anais eletrônicos [...]. Londrina: UEL, 2011. Disponível em: <http://www.uel.br/eventos/gpp/pages/arquivos/Linamar.pdf>. Acesso em: 5 mar. 2019.

ARRUDA, K. B. Os anúncios no jornal A União (1904-1937): a propagação da modernidade pedagógica na Paraíba. 2015. 76 f. Dissertação (Mestrado em Educação) - Universidade Federal da Paraíba, João Pessoa, 2015. 
BIANCHETTI, L.; FÁVERO, O. História e histórias da pós-graduação em educação no Brasil. Revista Brasileira de Educação, Rio de Janeiro, n. 30, p. 3-6, set./dez. 2005. DOI: https://doi.org/10.1590/s1413-24782005000300001

BURKE, P. O que é história cultural? Tradução de Sergio Goes de Paula. 2. ed. Rio de Janeiro: Jorge Zahar, 2008.

CHAGAS, F. G. Álbum das meninas, revista literária e educativa dedicada às jovens brasileiras: estudo de um impresso de Anália Franco (1898-1901). 2016. 186 f. Dissertação (Mestrado em Educação) - Universidade Federal de São Paulo, Guarulhos, 2016.

COSTA, A. M. B. de S. Civilização, modernidade e educação nas páginas do jornal A razão (1898-1923). 2017. 177 f. Tese (Doutorado em Educação) - Universidade Federal de Sergipe, São Cristóvão, 2017.

FERNANDES, F. M. Jornal O Albor e a produção/disseminação de feminilidades na imprensa lagunense: 1901-1930. 2014. 125 f. Dissertação (Mestrado em Educação) Universidade do Sul de Santa Catarina, Tubarão, 2014.

FERREIRA, N. S. de. As pesquisas denominadas "estado da arte". Educação \& Sociedade, Campinas, v. 23, n. 79, p. 257-272, ago. 2002. DOI: https://doi.org/10.1590/s0101$\underline{73302002000300013}$

CAPES. Coordenação de Aperfeiçoamento de Pessoal de Nível Superior. Ministério da Educação. Plataforma Sucupira. 2014. Disponível em: <http://www.capes.gov.br/avaliacao/plataforma-sucupira>. Acesso em: 20 set. 2017.

GINSZBURG, C. "Sinais: raízes de um paradigma indiciário". In: GINSZBURG, C. Mitos, emblemas, sinais: Morfologia e História. 1. reimp. São Paulo: Companhia das Letras, 1989. p. 143-180.

GONÇALVES JUNIOR, E. B. O impresso como estratégia de intervenção social: educação e história na perspectiva de Dario Vellozo (1885-1937). 2011. 104 f. Dissertação (Mestrado em Educação) - Universidade Federal do Paraná, Curitiba, 2011.

HOBSBAWM, E. Sobre história. São Paulo: Companhia das Letras, 1998.

LOMBARDI, J. C. História e historiografia da educação: atentando para as fontes. In: LOMBARDI, J. C.; NASCIMENTO, M. I. M. (orgs.). Fontes, história e historiografia da educação. Campinas: Autores Associados, 2004. p. 141-176.

MARACH, C. B. Inquietações modernas: discurso educacional e civilizacional no periódico A Escola (1906-1910). 2007. 114 f. Dissertação (Mestrado em Educação) - Universidade Federal do Paraná, Curitiba, 2007.

MARX, K. Manuscritos econômicos filosóficos e outros textos escolhidos. Traduções de José Carlos Bruni. 5. ed. São Paulo: Nova Cultural, 1991.

MARX, K. Contribuição à crítica da economia política. 3. ed. São Paulo: Martins Fontes, 2003. 
MENDES, V. da R.; IORA, J. A. A opinião dos estudantes sobre as exigências da produção na Pós-Graduação. Revista Brasileira de Ciências do Esporte, Brasília, v. 36, n. 1, p. 171-187, 2014. DOI: https://doi.org/10.1590/s0101-32892014000100012

NASCIMENTO, M. I. M. A primeira escola de professores dos Campos Gerais. Ponta Grossa: UEPG, 2008.

PASTRE, M. Clube curitibano: representações de lazer na formação da sociedade curitibana. 2009. 114 f. Tese (Doutorado em Educação) - Universidade Metodista de Piracicaba, Piracicaba, 2009.

POCOCK, J. G. A; MICELI, S. (orgs.). Linguagens do ideário político. São Paulo: Edusp, 2003.

RODRIGUES, M. B. F. Breve Definição. [201-?]. Disponível em: $<$ nei.ufes.br/sites/nei.ufes.br/files/RODRIGUES, $\% 20$ M.B.F. $\% 20 \mathrm{e} \% 20$ COELHO, $\% 20$ C.M. $\% 2$ 0Paradigma\%20Indiciário_Breve\%20definiçao.pdf>. Acesso em: 15 mar. 2019.

SAVIANI, D. A Pós-Graduação em Educação no Brasil: trajetória, situação atual e perspectivas. Revista Diálogo Educacional, Curitiba, v. 1, n. 1, p. 1-95, jan./jun. 2000. DOI: https://doi.org/10.7213/rde.v1i1.3211

SAVIANI, D. O legado educacional do regime militar. Caderno Cedes, Campinas, v. 28, n. 76, p. 291-312, set./dez. 2008.

SOUSA, N. L. O projeto republicano para a educação no Paraná e o processo de (des) mistificação de Júlia Wanderley. 119 f. 2013. Dissertação (Mestrado em Educação) Universidade Estadual de Ponta Grossa, Ponta Grossa, 2013.

SOUZA, E. F. de. Intelectuais, modernidade e discurso educativo no jornal "Diário dos Campos” (1909-1928). 2010. 159 f. Dissertação (Mestrado em Educação) - Universidade Estadual de Ponta Grossa, Ponta Grossa, 2010.

WASSERMAN, C. História intelectual: origem e abordagens. Revista Tempos Históricos, Marechal Cândido Rondon, v. 19, n. 1, p. 63-79, jan./jun. 2015.

ZANLORENZI, C. M. P. História da educação, fontes e a imprensa. Revista HISTEDBR Online, Campinas, n. 40, p. 60-71, dez. 2010. DOI: https://doi.org/10.20396/rho.v10i40.8639806

ZANLORENZI, C. M. P. A expressão do liberalismo na Revista A Escola (1906-1910) no Paraná. 2014. 143 f. Tese (Doutorado em Educação) - Universidade Estadual de Ponta Grossa, Ponta Grossa, 2014.

ZANLORENZI, C. M. P. A imprensa periódica na pesquisa sobre história da educação: um estado do conhecimento. Revista HISTEDBR On-line, Campinas, v. 18, n. 2[76], p. 385-400, abr./jun. 2018. DOI: https://doi.org/10.20396/rho.v18i2.8652374 